\title{
In memoriam Beatriz de la Fuente (I929-2005)
}

L a Vida de Beatriz de la Fuente estuvo dedicada en gran medida a la Universidad. Como docente y como investigadora, la doctora De la campo llegó a ser una sobresaliente especialista reconocida internacionalmente. Formó un considerable número de estudiantes, tanto en México como en el extranjero, muchos de ellos distinguidos investigadores en la actualidad.

De sus trabajos se han publicado quince volúmenes, la mayoría editados por la Universidad Nacional Autónoma de México, los cuales han merecido elogiosos comentarios de diversos especialistas. Entre sus obras está Los hombres de piedra. Escultura olmeca (1977), de la cual Michael D. Coe dijo: "es la más valiosa contribución, que debe ser leída tanto por los historiadores del arte como por los arqueólogos interesados en uno de los más fascinantes estilos artísticos".

En 1990 fundó el seminario multidisciplinario La Pintura Mural Prehispánica en México, y fue su directora desde entonces. Producto de su coordinación son dos volúmenes sobre pintura mural teotihuacana y cuatro acerca del área maya, todos ellos publicados por el Instituto de Investigaciones Estéticas de la UnAM. En 2005 terminó la preparación de otros dos volúmenes sobre la pintura mural prehispánica de Oaxaca.

Asimismo, publicó innumerables artículos y ponencias, dictó conferencias e impartió clases en diversas instituciones mexicanas y extranjeras, en las que dirigió tesis tanto de licenciatura como de maestría y doctorado. 


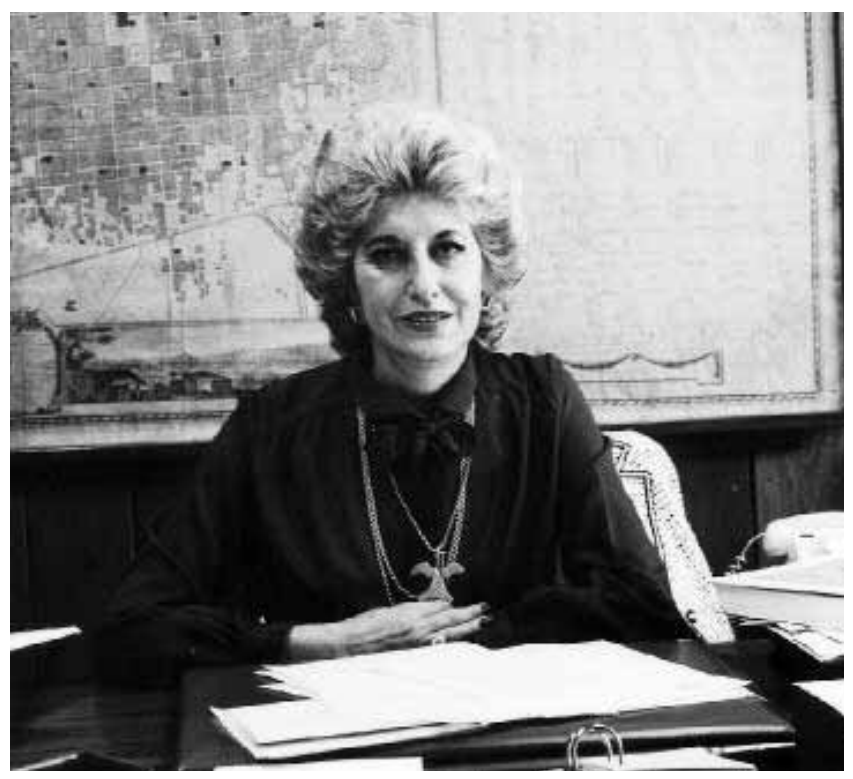

Doctora Beatriz de la Fuente. Foto: Pedro Cuevas, 1984. Archivo Fotográfico IIE-UNAM.

A lo largo de su carrera la doctora De la Fuente desempeñó importantes cargos académico-administrativos. Fue directora de la Escuela de Historia del Arte en la Universidad Iberoamericana, y en la unAm fue directora de la Colección de Arte de la Coordinación de Humanidades y de la Dirección General de Publicaciones, coordinadora del área de Historia del Arte en la Facultad de Filosofía y Letras, directora del Instituto de Investigaciones Estéticas y miembro de la Junta de Gobierno de nuestra máxima casa de estudios.

Fruto de su extraordinaria labor y dedicación son los reconocimientos de los que fue objeto tanto en México como en el extranjero: presidenta del Comité Mexicano de Historia del Arte, miembro de la Academia de Artes de México, de la Academia Mexicana de Historia, vicepresidenta del Comité International d'Histoire de l'Art y Premio Nacional de Ciencias y Artes; fue la primera mujer, y hasta el momento la única, miembro de El Colegio Nacional. La Universidad Nacional Autónoma de México le otorgó el Premio Universidad Nacional en I992 y la categoría de investigadora emérita en I996. \$ 